\title{
Quality of Life Questionnaire: Psychometric Properties and Relationships to Healthy Behavioral Patterns
}

\author{
Mercè Boixadós*, Modesta Pousada, Javier Bueno and Lourdes Valiente
}

Department of Psychology and Education, Universitat Oberta de Catalunya, Spain

\begin{abstract}
The main purpose of this study is to evaluate the quality of life in a healthy population from Universitat Oberta de Catalunya (UOC) using the "Quality of life Questionnaire" (QoLQ), which was developed in our cultural context and to examine its psychometric properties. A secondary goal is to explore the relationship between quality of life perception and healthy behavior profiles. Data were obtained from 264 participants with access to the online Campus who answered a web version of the questionnaire (QoLQ). Our results indicate that the psychometric properties of the instrument are satisfactory and the original factorial structure is confirmed: Social Support, General Satisfaction, Physical/Psychological well-being and Absence of work overload/Free time. The Cronbach's alpha coefficients for internal consistency ranged from 0.82 to 0.89 for the subscales and was 0.93 for the total items. A new variable called healthy behavioral pattern was generated from the answers of a chronogram of daily activities. The statistical significant differences (95\% CI and $\mathrm{t}$-values) across more healthy and less healthy behavior profiles reveal that the former perceive a higher quality of life.
\end{abstract}

Key Words: Quality of life Questionnaire, healthy behavior profile, internet user, psychometric properties.

\section{INTRODUCTION}

The concept of quality of life (QoL) is widely used in a highly diverse range of disciplines and contexts. Sociologists, physicians, psychologists and economists are among those using this concept routinely, with one of their main aims being to improve the living conditions of individuals and society alike.

It's widely accepted that the concept of QoL came into existence during the 1970s, in the field of medical science and connected to terms such as health and wellbeing. It became more widely used in the 1980s and its content gradually broadened until it came to encompass concern for "the subject's experience of their social life, their everyday activity and their own health" ([1], p. 1047). The same authors report that the concept gradually took on greater substance and became more complex.

The complexity of the concept is reflected in its definition [2,3]. For instance, the WHO, holds QoL to be an individual's perception of their position in life within their cultural context and system of values, and in relation to their ambitions, expectations, principles and concerns.

In this definition, a number of key characteristics emerge:

- QoL does not refer to the real, objective conditions in which the subject lives, but to their personal experience of those conditions.

\footnotetext{
*Address correspondence to this author at the Estudis de Psicologia i Ciències de l'Educació, Universitat Oberta de Catalunya-www.uoc.edu, Rambla del Poblenou 156, 08018 Barcelona; Tel: 933263 894; Fax: 933 568 822; E-mail: mboixados@uoc.edu
}

- That personal experience may change over the course of the subject's lifetime.

- Each individual may make a different appraisal, depending on their experiences, needs and desires.

- The cultural context and the reference value system must be taken into account.

All these complex characteristics lead to the difficulty of measuring QoL, because its evaluation has to take into account all of these aspects. In recent years, evaluations of QoL have grown more focused on the subjective component than on the analysis of objective variables that are external to the subject. Psychology therefore has a great deal to offer to the study of QoL, in terms of explaining how subjects perceive QoL, which processes enable to experience satisfaction and what elements constitute such an experience (see, for instance, [4]).

Furthermore, it is not theoretically clear whether QoL should be defined comprehensively or as a concept arising from a combination of various dimensions. As a result, there is a lack of methodological unanimity as far as measuring QoL is concerned. The instruments proposed to that end thus include those that provide a single measurement referring to the general satisfaction of the individual (for example, [5]), and others that assess different dimensions separately [6]. The dimensions in question usually include physical and mental health, social interaction and emotional state [7]. In the case of multidimensional instruments, a distinction is made between those developed for general application, regardless of the pathologies from which the population under assessment may be suffering, and those designed specifically to evaluate the QoL of populations with a particular pathology ([8], for more detailed information on 
the questionnaires available). Despite this heterogeneity of measure instruments, most of the empirical studies that assess quality of life tend to use two questionnaires, WHOQOL [9], or SF-36 [10], and focus on the quality of life in people with specific pathologies.

In fact, more often that not, the concept of QoL has been linked with the concept of health and with the new biopsychosocial model. This model is meant to overcome the traditional biomedical model that focuses on disease, its diagnosis and its treatment and, coming from a more inclusive standpoint, considers the boundaries between health and disease as being more diffuse, as in the case of chronic diseases $[11,12]$. From the standpoint of this model, the objective would be to promote a longer and more satisfactory life, emphasizing in particular the quality of life. It is therefore common in this context to use the term health-related quality of life (HRQoL).

Consequently, this new model understands health as being the result of interplay among physical, psychological and social factors in everyday life, i.e. the lifestyle of people, which plays a crucial role in the development of many of the diseases they suffer.

From a psychosocial approach, the concept of lifestyle refers to patterns of behavior shared by a social group related to the values, customs and fashions prevalent in a given time. Thus, the social and cultural context largely determines the lifestyle of people, and major changes in this context in turn generate changes in lifestyle [13].

Consequently, the climate of change that advanced societies are experiencing in the information society is generating a rich debate about the dangers, challenges and opportunities associated with this change. Thus, information overload, the need to manage this avalanche of information, its rapid obsolescence and how technology keeps us connected to work regardless of time or place, are all traits that lead us to doubt whether the network society favors a healthier lifestyle, or whether it instead generates a series of conditions that make such a lifestyle more difficult to achieve.

From this theoretical framework, our interest was to assess QoL, but in the context of a population whose most relevant characteristic is a frequent use of information technologies and, therefore, for being members of the new information and knowledge society. For this reason, the subjects that took part in our research were members of the Universitat Oberta de Catalunya (UOC), a university in which the interaction between students and professors take place through the Internet. Therefore, this work aims to evaluate the QoL of a sample group of subjects from the online Campus of the Universitat Oberta de Catalunya (UOC), to which end the quality of life questionnaire by Ruiz \& Baca [14] has been used. We chose the "Quality of Life Questionnaire" [14] for various reasons: first of all, the population studied did not have any specific illness in common and was mostly healthy, hence we felt that a questionnaire geared to a general population was more suitable; secondly, this questionnaire was developed in our cultural context and endorsed by a thorough psychometric study.
This work also seeks to study the relationship between quality of life and certain forms of conduct associated with a healthy behavioral pattern. In that respect, there are many people in the information society who show signs of leading a stressful life, one involving long working hours, travel, incompatible working and family lives, rushed meals, few hours of sleep, little in the way of free time, etc. Together, those factors would appear to entail an unhealthy behavioral pattern. How, though, do such people rate their quality of life?

Therefore a further objective of this research is to find out whether there is some relationship between behavior that could be classified as more healthy or less healthy and people's assessment of their own quality of life, as certain previous studies have indicated (for example, [15]).

In summary, the aims of this work are as follows:

1- To use the quality of life questionnaire Ruiz \& Baca [14] to assess the way in which a sample group of subjects from the Virtual Campus of the UOC perceive their QoL, and to analyze the questionnaire's psychometric properties.

2- To perform a comparative study of the QoL of two sub-sample groups of subjects based on their correspondence to a behavioral pattern defined as more or less healthy.

\section{METHOD}

\section{Subjects}

There were a total of 264 participating subjects with access to the Virtual Campus of the Universitat Oberta de Catalunya (UOC); $70.3 \%$ of the subjects were females and $29.7 \%$ males. Their average age was 33 (DT=8.48). The most relevant characteristic is a frequent use of information technologies, $95 \%$ use mobile phones, $95.5 \%$ use computers; $44.1 \%$ use laptop computers and $17.8 \%$ use handheld computers. All of them use Internet and $62.7 \%$ of them more than 5 years ago.

As stated in the introduction, the sample group of subjects was taken from a generally healthy population. $85.5 \%$ stated that they had suffered from some kind of physical ailment over the previous year, although of an isolated rather than a chronic nature. Very similarly, $82.5 \%$ said that they had suffered from an isolated psychological problem during the previous year. Additionally, 63.4\% did not smoke, $98.6 \%$ drank less than three glasses of wine or beer per day and $99.5 \%$ refrained from the consumption of cocktails or liqueurs on working days. Table 1 contains a summary of other sociodemographic data corresponding to the subjects who took part.

\section{Instruments}

\section{The Instruments Used were as Follows}

- Quality of life questionnaire (QoLQ/CCV spanish version): this generic questionnaire consists of 39 items, with a five-point Likert-type scale from Never (1) to Always (5). It was designed and validated by Ruiz \& Baca [14] and used with a healthy Spanish population. They concluded that the 
items could be were grouped into four dimensions, namely Social support (9 items for people without partners: from 20 to 28; and 13 for people with partners: the same items, plus from 36 to 39), General satisfaction (13 items:1, 2, 4, 11, from 17 to 19 and from 30 to 35), Physical/psychological wellbeing (7 items: 9, 10 and from 12 to 16) and Absence of excessive workload/free time (6 items: 3 , from 5 to 8 and 29 ). The percentage of variability of the four factors in the questionnaire was $53.5 \%$. That percentage was distributed as $17.82 \%$ in the case of the first factor, $15.84 \%$ in that of the second, $10.02 \%$ in that of the third and $9.82 \%$ in that of the fourth. The Cronbach alpha internal consistency indices found by these authors for each dimension ranged between 0.82 and 0.91 , and the internal consistency of the total questionnaire score was 0.94 .

Table 1. Sociodemographic Description of the Participating Subjects

\begin{tabular}{|c|c|}
\hline \multicolumn{2}{|l|}{ Marital status } \\
\hline Married / with a partner & $54.5 \%$ \\
\hline Single & $41.3 \%$ \\
\hline Divorced/separated & $4.2 \%$ \\
\hline \multicolumn{2}{|l|}{ Number of children } \\
\hline No children & $52.3 \%$ \\
\hline One & $23.4 \%$ \\
\hline Two & $12 \%$ \\
\hline More than two & $12 \%$ \\
\hline \multicolumn{2}{|l|}{ Relationship with the UOC } \\
\hline Students & $76.8 \%$ \\
\hline Staff & $11.8 \%$ \\
\hline External lecturers & $8.7 \%$ \\
\hline Others & $2.7 \%$ \\
\hline \multicolumn{2}{|l|}{ Field of study } \\
\hline Psychology & $29.4 \%$ \\
\hline Business studies & $12.6 \%$ \\
\hline Work studies & $11.3 \%$ \\
\hline \multicolumn{2}{|l|}{ Completed studies } \\
\hline Secondary education & $18.2 \%$ \\
\hline General degree & $34.1 \%$ \\
\hline Honours degree & $28.8 \%$ \\
\hline Doctorate & $6.8 \%$ \\
\hline Others & $12.1 \%$ \\
\hline \multicolumn{2}{|l|}{ Annual family income } \\
\hline$>€ 24,000$ & $51.8 \%$ \\
\hline between $€ 12,000$ and $€ 24,000$ & $36.4 \%$ \\
\hline$<€ 12,000$ & $11.9 \%$ \\
\hline
\end{tabular}

Table 1 contd....

\begin{tabular}{|c|c|}
\hline First use of internet & \\
\hline$>5$ years ago & $62.7 \%$ \\
\hline Between 2 and 4 years ago & $34.2 \%$ \\
\hline$<2$ years ago & $3.1 \%$ \\
\hline \multicolumn{2}{|l|}{ Able to read English } \\
\hline Yes & $82.4 \%$ \\
\hline No & $17.6 \%$ \\
\hline \multicolumn{2}{|l|}{ Employed } \\
\hline Yes & $87.9 \%$ \\
\hline No & $12.1 \%$ \\
\hline \multicolumn{2}{|c|}{ Work in a health-related field } \\
\hline Yes & $16.5 \%$ \\
\hline No & $83.5 \%$ \\
\hline \multicolumn{2}{|l|}{ Use of mobil phones } \\
\hline Yes & $95 \%$ \\
\hline No & $5 \%$ \\
\hline \multicolumn{2}{|l|}{ Use of computers } \\
\hline Yes & $95.5 \%$ \\
\hline No & $4.5 \%$ \\
\hline \multicolumn{2}{|l|}{ Use of laptop computers } \\
\hline Yes & $95.5 \%$ \\
\hline No & $4.5 \%$ \\
\hline
\end{tabular}

- Chronogram of a working day: this consists of 10 questions (created adhoc) which tried to capture the approximate amount of time devoted to different daily activities, specifically sleeping, eating breakfast, lunch and dinner, free time, sitting down, standing up, walking, exercising and recreational pursuits. The questions concerning specific behaviors related to dimensions or axes in relation to lifestyle were the result of a review of the literature on the subject [16-19]. We chose those items that the literature considers clearly related with healthy habits (e.g. sleeping enough every day; doing exercise or physical activity, having free time, etc...). The chronogram gave the approximate time that the subjects reported spending on different daily activities, which made it possible to distinguish between more or less healthy behaviors, on the basis of the time devoted to the activities in question. These items were divided into two groups (healthy and unhealthy) using the criteria shown in Table 2, reviewed by experts working in the health field. We calculated an unhealthy behavioral score by adding up the points allocated for answers representing unhealthy behavior. A decision was thus made to dichotomize the subjects' responses and to regard their behavior as unhealthy if they slept for less than 6 hours, ate breakfast in less than 15 minutes, ate lunch and dinner in less than 30 minutes, had less than 2 hours of free time per day, spent more than 8 hours sitting down, spent more than 6 hours on their feet, walked 
for less than 15 minutes a day, did not do any exercise and devoted less than 15 minutes per day to recreational pursuits. On the other hand, behavior that did not meet those criteria was regarded as healthy.

There were 10 everyday activities that made it possible to subdivide the sample to obtain two extremes groups related to their healthy behavior and thus generate a new variable called the healthy behavioral pattern. Specifically, the criteria was that subjects who obtained 2 or less points on the unhealthy behavior score were in the group labeled more healthy behavioral pattern, and subjects who scored 5 or more points were in the group labeled less healthy behavioral pattern (See Table $\mathbf{3}$ ).

\section{Procedure}

Data was collected by means of an online questionnaire posted on an internal web page of the UOC, which was only accessible to members of its community. It was possible to control for repeat responders and guarantee anonymity. The questionnaire was available for 3 months in the Catalan and Spanish versions of the online Campus. On the first screen, prior to seeking consent, an explanation of how to answer the questions was provided and the various options as regards replies were mentioned. It was repeatedly stated that no items should be left unanswered, to avoid omissions

\section{RESULTS}

\section{Psychometric Study of The Quality of Life Questionnaire (QoLQ/CCV)}

The analyses performed included a principal component analysis (PCA) of the QoLQ/CCV, for confirmatory pur- poses [20]. The number of factors to be extracted was forced to four, and the factor loadings of the rotated factor matrix (varimax rotation) interpreted. The Cronbach alpha index of all the questionnaire's items and of each subscale was calculated, verity the level of internal consistency.

It was decided that this section should contain the results of the 39 items, i.e. those corresponding to the subjects with a partner $(\mathrm{N}=184)$. A check was carried out beforehand to ensure that the 35-item factor structure, encompassing all the subjects $(\mathrm{N}=264)$, with and without partners, did not differ from the factor structure of the solution presented here.

As can be seen in the rotated factor solution presented in Table 4, the 39 items were maintained and grouped into the 4 factors envisaged, all of which had a factor loading of over 0.3 . The items related to Social support (SS-13 items) were weighted in the first factor, those associated to General satisfaction (GS-12 items) in the second, those referring to Physical/psychological wellbeing (PPW- 7 items) in the third, and those corresponding to Absence of excessive workload/free time (AWOF-7 items) in the fourth. A comparison between this structure factor and the original version of Ruiz \& Baca [14] revealed that item 30, "Are you able to pursue your pastimes (time, money, etc.)?”, which was originally weighted in the General satisfaction subscale, had been given a greater weighting in the Absence of excessive workload/free time dimension. A decision was made to keep the item in its new location, because its wording makes it possible to interpret that it is better suited to the dimension related to free time.

Overall, the four factors explain $51.72 \%$ of the total variability. That percentage is distributed fairly equally, with

Table 2. Criteria for an Unhealthy Behavior Score

\begin{tabular}{|c|c|c|}
\hline Items of Daily Activities & 1 Point (Unhealthy) & 0 Point (Healthy) \\
\hline \hline sleeping & Less than $6 \mathrm{~h}$ & $6 \mathrm{~h}$ or more \\
\hline eating breakfast & Less than $15 \mathrm{~min}$ min or more \\
\hline lunch & Less than $30 \mathrm{~min}$ & 30 min or more \\
\hline dinner & Less than 30 min & $2 \mathrm{~h}$ or more per day \\
\hline free time & Less than $2 \mathrm{~h}$ per day & Less than $2 \mathrm{~h}$ per day \\
\hline sitting down & $8 \mathrm{~h}$ or more per day & $6 \mathrm{~h}$ or more per day \\
\hline standing up & Less than $6 \mathrm{~h}$ per day & 15 min or more per day \\
\hline walking & Less than 15 min per day & 15 min or more per day \\
\hline exercising & Less than 15 min per day & 15 min or more per day \\
\hline recreational pursuits & Less than 15 min per day & \\
\hline
\end{tabular}

Table 3. Criteria for a Healthy Behavioral Pattern

\begin{tabular}{|l|c|c|}
\hline Healthy Behavioral Pattern & Less Healthy & More Healthy \\
\hline \hline Unhealthy behavioral score & 5 or more Points & 2 or less Points \\
\hline
\end{tabular}


Table 4. Rotated Factor Matrix Interpretation of the QoLQ/CCV Items

\begin{tabular}{|c|c|}
\hline \multicolumn{2}{|r|}{ Quality of life questionnaire $(\mathrm{QoLQ} / \mathrm{CCV})(\mathrm{No}$. of items $=39$; variability $=51.72 \% ; \alpha=0.93)$} \\
\hline Factor weightings & $\begin{array}{l}\text { FACTOR } 1 \text { - SOCIAL SUPPORT }(\text { SS }) \\
(\text { Explained variability }=6.1 ; \text { variability }=15.64 \% ; \text { number of items }=13 ; \alpha=0.89)\end{array}$ \\
\hline 0.78 & 36. Are you satisfied with your partner? \\
\hline 0.73 & 37. Are you physically attracted to your partner? \\
\hline 0.72 & 24. Do you feel that you have someone to turn to when you need company or support? \\
\hline 0.72 & 39. Are you satisfied with your family (partner and/or children)? \\
\hline 0.70 & 38. Does your partner satisfy your sexual desires and needs? \\
\hline 0.68 & 21. Do you feel loved by the people who are important to you? \\
\hline 0.65 & 27. Are you satisfied with your friends? \\
\hline 0.62 & 20. Do you have a satisfactory relationship with those with whom you live? \\
\hline 0.62 & 23. Do you have friends on whom you can rely if necessary? \\
\hline 0.60 & 26. Do you have someone with whom you can share your free time and pastimes? \\
\hline 0.54 & 28. Do you find your social life satisfactory? \\
\hline 0.52 & 22. Do you have a good relationship with your family? \\
\hline-0.38 & 25. Would you like to have more satisfying sexual relations? If you do not have sexual relations, would you like to? \\
\hline Factor weightings & $\begin{array}{l}\text { FACTOR 2- GENERAL SATISFACTION }(\mathrm{GS}) \\
(\text { Explained variability }=5.48 ; \text { variability }=14.04 \% ; \text { number of items }=12 ; \alpha=0.89)\end{array}$ \\
\hline 0.77 & 01. Do you enjoy your work? \\
\hline 0.70 & 17. Do you believe that you are fulfilling your ambitions? \\
\hline 0.68 & 19. Do you feel capable of obtaining most of the things you desire? \\
\hline 0.68 & 32. Do you regard your life as interesting? \\
\hline 0.68 & 18. Do you feel that life is meeting your expectations? \\
\hline 0.63 & 02. Are you happy with the way you work? \\
\hline 0.63 & 33. Are you satisfied with your life? \\
\hline-0.57 & 11. Do you consider yourself to be a failure? \\
\hline 0.52 & 31. Do you regard your life as pleasant? \\
\hline 0.51 & 04. Are you happy with your working environment? \\
\hline 0.49 & 34. Are you satisfied with the money at your disposal? \\
\hline 0.43 & 35. Are you satisfied with the way you are? \\
\hline Factor weightings & $\begin{array}{l}\text { FACTOR 3- PHYSICAL/PSYCHOLOGICAL WELLBEING }(\mathrm{PPW}) \\
(\text { Explained variability }=4.5 ; \text { variability }=11.54 \% ; \text { number of items }=7 ; \alpha=0.88)\end{array}$ \\
\hline-0.75 & 14. Do you suffer from insomnia or significant problems getting to sleep? \\
\hline 0.70 & 16. Are you satisfied with your current state of health? \\
\hline 0.68 & 09. Do you feel that you are in good health? \\
\hline-0.67 & 13. Do you have concerns that prevent you from relaxing or sleeping, or which make it difficult for you to do so? \\
\hline-0.65 & 15. Do you spend most of the day feeling tired? \\
\hline-0.63 & 12. Do you feel worried or distressed? \\
\hline 0.57 & 10. Do you feel that you have enough energy for your day-to-day life? \\
\hline Factor weightings & $\begin{array}{l}\text { FACTOR 4- ABSENCE OF WORK OVERLOAD/FREE TIME (AWOF) } \\
\text { (Explained variability }=4.09 ; \text { variability }=10.5 \% \text {; number of items }=7 ; \alpha=0.82 \text { ) }\end{array}$ \\
\hline 0.67 & 29. Do you have enough time to relax and enjoy yourself every day? \\
\hline-0.62 & 06. At the end of a working day, do you feel so tired that all you want to do is rest? \\
\hline-0.59 & 08. Do you have too much work at present? \\
\hline 0.59 & 03. Does your work leave you enough free time for other things that you want to do? \\
\hline 0.59 & 30. Are you able to pursue your pastimes (time, money, etc.)? \\
\hline-0.55 & 07 Are you permanently tense as a result of your work? \\
\hline-0.43 & 05. Do work-related problems or concerns prevent you from enjoying your free time? \\
\hline
\end{tabular}

$15.64 \%$ in the case of the first factor, $14.04 \%$ in that of the second, $11.54 \%$ in that of the third and $10.5 \%$ in that of the fourth. As Table 4 shows, the Cronbach alpha internal consistency index arising from the total score corresponding to the questionnaire was $\alpha=0.93$. As regards the different subscales, the $\alpha$ indices obtained were 0.89 for Social support and General satisfaction, 0.88 for Physical/ psychological wellbeing and 0.82 for Absence of excessive workload/free time. 


\section{Descriptive Statistics}

Once the psychometric properties of the QoLQ/CCV had been analyzed, scores were calculated for the entire scale and for each of the 4 dimensions, on the basis of the generation of additive scales. In other words, the direct scores of the items were used to generate the mean score of each of the dimensions in question. Table 5 contains a summary of the descriptive statistics corresponding to the total mean score for the questionnaire and each dimension. It can be observed that the mean and median of the subjects' mean scores are very similar. Additionally, it can be said that the subjects' perception of their quality of life is quite satisfactory $(\mathrm{m}=3.82$; $\mathrm{DT}=0.44)$. An examination of the descriptive statistics by dimensions shows that the dimension in which the level of satisfaction is the highest is Social support $(\mathrm{m}=4.20$; $\mathrm{DT}=0.54)$, while the lowest level of satisfaction, in relation to the other dimensions, corresponds to Absence of excessive workload/free time $(\mathrm{m}=3.32 ; \mathrm{DT}=0.64)$.

\section{Comparative Study Between Healthy Behavioral Patterns}

As stated previously, the sample group consisted of subjects who could generally be classified as healthy. Nevertheless, the chronogram enabled us to distinguish between two extremes of the healthy behavioral pattern shown in Tables 2 and 3 criteria. Specifically, subjects who carried out 5 or more activities in an unhealthy manner were deemed to have a less healthy behavioral pattern $(n=64)$, whereas, those who carried out a maximum of 2 activities in an unhealthy manner were held to have a more healthy behavioral pattern $(\mathrm{n}=81)$.

An analysis was subsequently carried out to find out the scores obtained by the two groups of subjects in the QoL questionnaire. As can be seen in Fig. (1), which indicates the means and confidence intervals $(95 \%)$ of the quality of life subscales (SS: Social support; GS: General satisfaction; PPW: Physical/psychological wellbeing; AWOF: Absence of

Table 5. Descriptive Statistics for Total Quality of Life Score and for the Four Dimensions

\begin{tabular}{|c|c|c|c|c|c|c|}
\hline & Mean & S. D. & Min & Max & Median & N* \\
\hline \hline SS & 4.20 & 0.54 & 1.92 & 5 & 3.31 & 3.75 \\
\hline GS & 3.72 & 0.55 & 1.83 & 5 & 3.71 & 3.29 \\
\hline PPW & 3.74 & 0.62 & 1.29 & 5 & 5 & 258 \\
\hline AWOF & 3.32 & 0.64 & 1.57 & 4.79 & 3.85 \\
\hline Total QoLQ/CCV & 3.82 & 0.44 & 2.54 & 184 \\
\hline
\end{tabular}

SS: Social support; GS: General satisfaction ; PPW: Physical/psychological wellbeing; AWOF: Absence of excessive workload/free time; Total QoLQ: Quality of life questionnaire *The size of the sample in the Social support subscale is smaller due to the fact that some items of this subscale can only be answered by people with a partner.

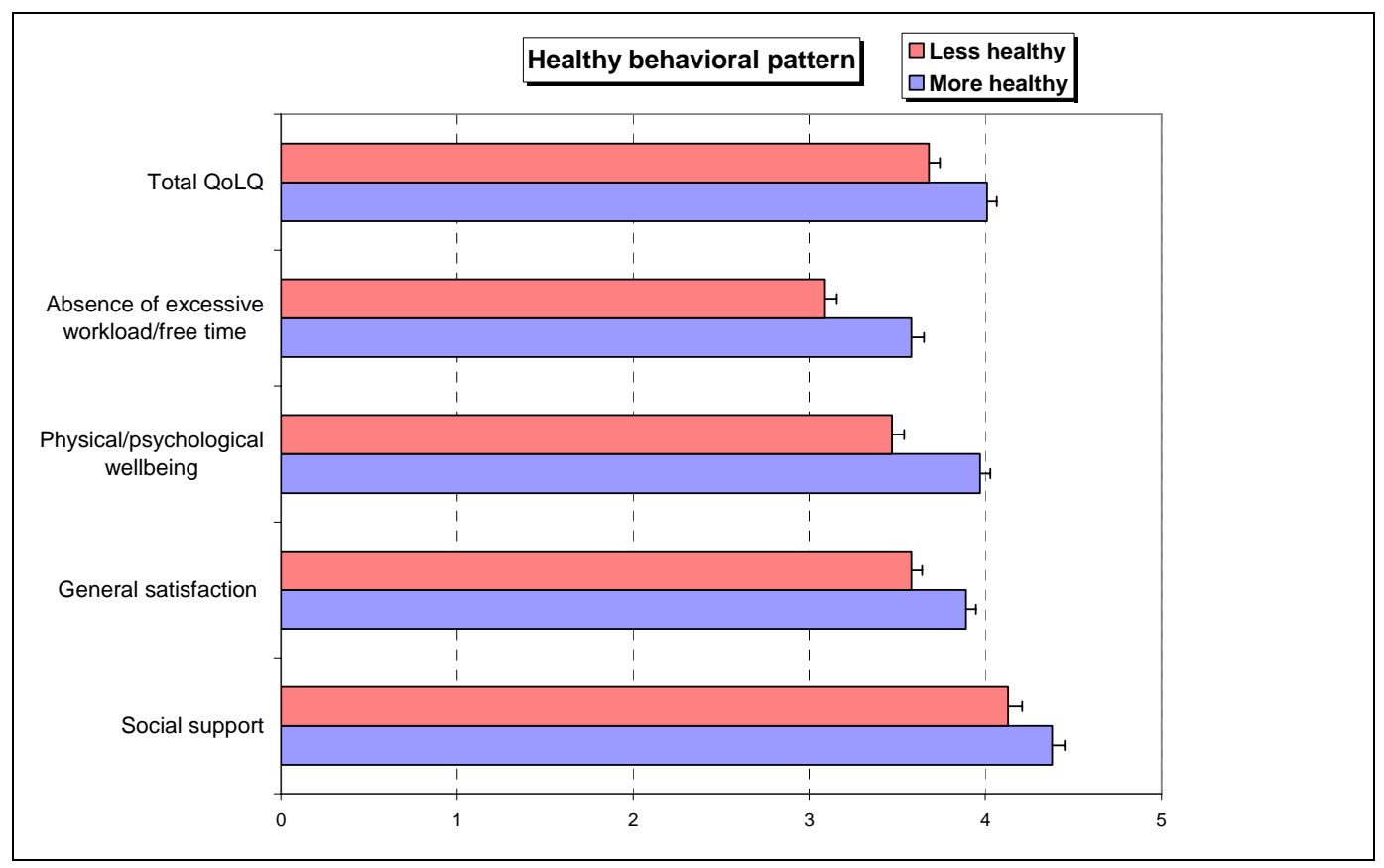

Fig. (1). Mean and confidence interval (95\%) for the four scales and for total quality of life score in two healthy behavioral pattern (More healthy/ Less healthy). 
excessive workload/free time) corresponding to Table 6, the subjects' scores for each of those subscales varied on the basis of whether their behavioral pattern was more or less healthy. The data can be summarized by highlighting that the subjects with a healthier daily behavioral pattern have statistically higher scores both where the overall quality of life score and the four questionnaire subscales are concerned (See t-values in Table 6).

\section{DISCUSSION}

The discussion is divided into two main sections, which correspond to the two aims of the study, i.e. the analysis of the psychometric properties of the generic quality of life questionnaire of Ruiz \& Baca [14], on one hand; and the comparative study of the healthy behavioral pattern in relation to quality of life, on the other.

With regard to the former, the results obtained confirm the multidimensional nature of the quality of life construct, and the factor structure of the questionnaire reflects the four factors identified by Ruiz \& Baca [14], namely Social support, General satisfaction, Physical and psychological wellbeing and Absence of excessive workload/free time. The four factors explain $51.72 \%$ of the total variability. The Cronbach $\alpha$ internal consistency indices stand at 0.93 where the total is concerned, and vary between 0.82 and 0.89 in the case of subscales. The indices are regarded as being completely acceptable.

The only difference between the factor structure found in this study and that originally proposed by Ruiz \& Baca [14] lies in item 30, "Are you able to pursue your pastimes (time, money, etc.)?". While the item in question was more highly weighted in the General satisfaction factor in the original study, it is given greater weighting in the Absence of excessive workload/free time dimension in the current work. It can be argued that this change from one dimension to another may be linked to the type of sample group studied. Ruiz \& Baca [14] administered the questionnaire to subjects from a general population, aged between 18 and 65, and with a nonuniversity level of education. In contrast, this study has seen the questionnaire administered to subjects from a university community, aged between 25 and 41, with an advanced level of studies $(70 \%)$, who are currently studying and working, and predominantly consist of females (70\%) with family responsibilities. It could be said that this sample group is made up of subjects from the information and knowledge society, who typically tend to have a highly active lifestyle (working, studying, looking after families and homes, etc.) and attribute particular importance to time and its management. It is for that reason that they assigned a higher score to the time factor than other possible factors in the case of item 30 , with greater weighting in the dimension related to excessive workloads and free time than in that of general satisfaction.

Although it has to be said that the perception of the quality of life of the sample group analyzed is generally fairly satisfactory, the descriptive results show that the Absence of excessive workload/free time dimension was given the lowest score in comparison with the others.

As mentioned the introduction, management of time is precisely one of the aspects that most influence having a lifestyle characterized by the network society. This is related to the ability to put new technologies at our disposal to overcome barriers of space and time.

As mentioned in the introduction, management of time is precisely one of those aspects that most influence having a lifestyle characterized by the network society. This is related to the ability to put new technologies at our disposal to overcome barriers of space and time.

Thus, for example, mobile devices and the Internet allow people to attend to work tasks anywhere and anytime, which largely removes the boundaries between personal time and work time. When we can be connected to our work anywhere and at any time, our capacity and flexibility to self-organize increases, but, similarly, we run the risk of allowing work tasks to invade our free time. Learning to connect is easy, but we also need to learn to "disconnect", and this seems to be more difficult to do.

On the other hand, the subjects of our sample had higher satisfaction scores in the Social Support dimension, which is consistent with the use of communication and information technologies. It is true that being constantly connected can contribute to a certain work overload, but at the same time it can also help maintain or even increase contact with the

Table 6. Mean, SDs, t-values and Confidence Interval (95\%) for the Difference for the Four Dimensions and for Total Quality of Life Score between two Means in Healthy Behavioral Pattern (More Healthy/ Less Healthy)

\begin{tabular}{|c|c|c|c|c|c|c|c|c|c|c|}
\hline & \multicolumn{3}{|c|}{ More Healthy } & \multicolumn{3}{c|}{ Less Healthy } & \multicolumn{2}{c|}{ C. I.(95\%) } \\
\hline & Mean & S.D. & N & Mean & S.D. & N & t & df & Diff. & p \\
\hline \hline SS & 4.38 & 0.50 & 50 & 4.13 & 0.57 & 53 & 2.34 & 101 & 0.021 & $0.04-0.46$ \\
\hline GS & 3.89 & 0.44 & 63 & 3.58 & 0.53 & 76 & 3.76 & 137 & $<0.001$ & $0.15-0.47$ \\
\hline PPW & 3.97 & 0.47 & 64 & 3.47 & 0.61 & 77 & 5.34 & 139 & $<0.001$ & $0.31-0.68$ \\
\hline AWOF & 3.58 & 0.57 & 63 & 3.09 & 0.59 & 78 & 4.99 & 139 & $<0.001$ & $0.30-0.69$ \\
\hline Total QoLQ/CCV & 4.01 & 0.38 & 49 & 3.68 & 0.43 & 50 & 4.05 & 97 & $<0.001$ & $0.17-0.50$ \\
\hline
\end{tabular}

SS: Social support; GS: General satisfaction; PPW: Physical/psychological wellbeing; AWOF: Absence of excessive workload/free time; Total QoLQ: Quality of life questionnaire. *The size of the sample in the Social support subscale is smaller due to the fact that some items of this subscale can only be answered by people with a partner. 
environment (friends, family, leisure activities, etc.) This is what seems to be the case judging from the responses of our study participants.

In connection with the importance attributed to managing time in the information society, the second aim of the study was to analyze the relationship between the time that the subjects in the sample group spent behaving in certain ways deemed to be positive as regards their health and quality of life. Specifically, the assessment of the behavior in question took into account the amount of time devoted to sleeping, eating breakfast, lunch and dinner, free time, sitting down, standing up, walking, exercising and recreational pursuits on a daily basis. All these behaviors are related to some of the main variables of a healthy lifestyle, such as eating habits, physical activity, rest habits and free time activities [21]. Nonetheless, it must be borne in mind that this is not a question of lifestyles in their own right, as no account is taken of its qualitative nature (for example, the type of food consumed, in the case of eating habits). Only the time-related aspect is considered, i.e. the time spent on each of the activities. It is for this reason that we refer to these behaviors as a healthy behavioral pattern and not as a healthy lifestyle.

Results indicate that the subjects with a more healthy daily behavioral pattern also enjoy greater quality of life. This result is reproduced in the case of the overall quality of life questionnaire score and in that of each individual dimension. Thus, those participants with a healthier pattern of behavior show greater overall satisfaction with their lives; greater social support; increased well-being, both physical and psychological; and less work overload.

As mentioned earlier, the healthy behavioral pattern resembles a healthy lifestyle in certain ways. Studies on the relationship between lifestyle and quality of life can therefore be used for the purpose of discussing the results generated in this research. In that respect, little attention has yet been paid to the relationship between lifestyle and quality of life in the general population. One reason for this could be that quality of life has often been assessed by means of the SF-36 health questionnaire, which measures quality of life in relation to health, and among populations suffering from some kind of physical illness or psychological disorder [22, 23]. This work differs from these studies in that it is based upon a healthy population.

There are very few studies that relate lifestyle and quality of life in healthy people. In general, existing work analyses the relationship between QoL and a specific habit, such as the consumption of alcohol [24] or tobacco [25].

In one study conducted by Kimura et al. [15], the relationship between QoL (evaluated by means of the SF-36 health questionnaire) and certain lifestyle habits (appraised by means of a series of questions posed to the subjects in the sample group) is analyzed. The results obtained by those authors are congruent with those produced in this work. For example, they found that working overtime, which could be related to not having time for recreational pursuits in our study, reduced quality of life in both physical and mental terms. They also observed that physical exercise, which, in the case of our study, could be related to time spent sitting down, standing up, walking and exercising, is associated with greater quality of life.

Finally, having a set of data on a reduced number of habits (as is the case of Kimura et al., [15]) or an estimation of the time that subjects spend on certain daily activities (as is the case of this study) is probably not enough to be able to perform an in-depth analysis of the relationships between QoL and lifestyle. More complete information on the lifestyle of the subjects analyzed is required. We are therefore working on the development of a lifestyle questionnaire that deals as exhaustively as possible with the variables that constitute a healthy lifestyle. In the future, such a questionnaire should make it possible to find out which types of behavior are most directly related to the subjects' perception of wellbeing. This information could prove to be very relevant in the fields of education and the promotion of health.

We are conscious of the limitations of Internet methods in data collection as we are aware that they will result in a bias in terms of self-selected samples and a relative lack of representation. In the present study, the members of the population were Internet users and respondents were already habitual Internet users; therefore using an online questionnaire had some advantages related to getting access to this population, ecological benefits, and was less expensive and time-consuming than traditional data collection methods.

A number of studies have evaluated and compared the Internet for survey research with traditional methods [26-28] and suggested that the data provided by Internet methods are at least of as good quality as those provided by traditional methods.

\section{ACKNOWLEDGEMENTS}

This work has been funded partly with grants SEC200303403 from Plan Nacional of I+D.

The authors would like to thank Beni Gómez their helpful comments and suggestions to the manuscript.

\section{REFERENCES}

[1] Moreno B, Ximenez C. Evaluación de la calidad de vida. [Evaluation of the quality of life ]. In: Buela-Casal G, Caballo VE, Sierra JC, Eds. Manual de Evaluación en Psicología clínica y de la salud [Manual of Evaluation in Clinical Psychology and Health]. Madrid: Siglo XXI, 1996; 1045-70.

[2] Church MC. The conceptual and operational definition of quality of life:a systematic review of the literature. 2004. [Retrieved January 24, 2006]. Available from: https://txspace.tamu.edu/bitstream/1969. 1/2771/1/etd-tamu-2004B-HEED-Church.pdf

[3] Eiser C, Greco V, Vance YH, Home B, Glaser A. Perceived discrepancies and their resolution: quality of live in survivors of childhood cancer. Psychol Health 2004; 19(1): 15-28.

[4] Sirgy MJ. The Psychology of Quality of Life. Dordrecht: Kluwer Academic Publishers 2002.

[5] Shin DC, Johnson DM. Avowed happiness as an overall assessment of the quality of life. Soc Indic Res 1978; 5: 475-92.

[6] Cobb CW. Measurement tools and the quality of life. [2000. Retrieved January 24, 2006]. Available from: http://www.rprogress. org/newpubs/2000/measure_qol.pdf

[7] Cieza A, Stuki G. Content comparison of health-related quality of life (HRQOL) instruments based on the international classification of functioning, disability and health (ICF). Qual Life Res 2005; 14: 1125-37.

[8] International Society for Quality of Life Studies. Directory of Instruments to measure Quality of Life. 2005. [Retrieved January 26, 2006]. Available from: http://acqol.deakin.edu.au/instruments/ instrument.php 
[9] World Health Organization. WHOQOL Measuring quality of life. WHO/MSA/MNH/PSF/97.4. Geneva: WHO, 1997. [Retrieved February 10, 2009]. Available from: http://www.who.int/mental_health/ media/68.pdf

[10] Ware JE, Snow KK, Kosinski M, Gandek B. SF-36® Health Survey Manual and Interpretation Guide. Boston, MA: New England Medical Center, The Health Institute 1993.

[11] Carr AJ, Gibson B, Robinson PG. Is quality of life determined by expectations or experience? BMJ 2001; 322: 1240-3.

[12] Kaplan RM. The significance of quality of life in health care. Qual Life Res 2003; 12(Suppl 1): 3-16.

[13] Coreil J, Levin JS, Gartly E. Estilo de vida. Un concepto emergente en las ciencias sociomédicas. [Lifestyle. An emerging concept in sociomedical sciences] Clín Y Salud 1992; 3(3): 221-31.

[14] Ruiz MA, Baca E. Design and validation of the Quality of Life Questionnaire ("Cuestionario de Calidad de Vida", CCV): a generic heath-related perceived quality of life instrument. Eur J Psychol Assess 1999; 9: 19-32.

[15] Kimura T, Ogushi Y, Takahashi M, Munakata Y, Ishii S. Association of health-related quality of life with health examination including organic functions and lifestyles in Japanesse employees. Qual Life Res 2004; 13: 519-29

[16] Blanchard C, Stein K, Baker F, Dent M, Denniston M, Couneya K, Nehl E. Association between current lifestyle behaviours and health-related quality of life in breast, colorectal, and prostate cancer survivors. Psychol Health 2004; 19: 1-13.

[17] Matsushita T, Matsushima E. Quality of life and lifestyle among city dwellers participating in the medical programs. Psychiatr Clin Neurosci 2004; 58: 642-50.

[18] Pronk N, Anderson L, Crain L, et al. Meeting recommendations for multiple healthy lifestyle factors. Prevalence, clustering, and predictors among adolescent, adult, and senior health plan members. Am J Prev Med 2004; 27: 25-33.

[19] Tashiro J. Exploring health promoting lifestyle behaviours of Japanese college women: perceptions, practices and issues. Health Care Women Int 2002; 23: 59-70.

[20] Viladrich C, Doval E, Prat R, Vall-Llovera M. Psicometría: metodología para la construcción de instrumentos de evaluación psicológica. [Psychometrics: methodology for the psychological evaluation instruments construction]. Barcelona: UAB 1999.

[21] Pastor Y, Balaguer I, García-Merita M. Estilo de Vida y Salud. [Lifestyle and Health] Valencia: Albatros 1999.

[22] Strube MJ, Berry JM, Goza BK, Fennimore, D. Type A behavior, age, and psychological well-being. J Pers Soc Psychol 1985; 49: 203-18.

[23] Rejeski WJ, Focht BC, Messier SP, Morgan T, Pahor M, Penninx B. Obese, older adults with knee osteoarthritis: weight loss, exercise, and quality of life. Health Psychol 2002; 21: 419-26.

[24] Volc RJ, Cantor SB, Steinbauer JR, Cass AR. Alcohol use disorders, consumption patterns, and health-related quality of life of primary care patients. Alcoholism: Clin Exp Res 1997; 21: 899905.

[25] Wilson D, Parsons J, Walefield M. The health- related quality of life of never smokers, ex-smokers, and light, moderate, and heavy smokers. Prev Med 1999; 29: 139-44.

[26] Birnbaum MH. Human research and data collection via the internet. Ann Rev Psychol 2004; 55: 803-32.

[27] Eysenbach G, Wyatt J. Using the Internet for Surveys and Health Research. J Med Internet Res 2002; 4(2). Retrieved February 10, 2009 Available from: http://www.jmir.org/2002/2/e13/

[28] Gosling SR, Vazire S, Srivastava S, John OP. Should we trust web-based studies? A comparative analysis of six preconceptions about internet questionnaires. Am Psychol 2004; 59(2): 93-104.

(c) Boixadós et al.; Licensee Bentham Open.

This is an open access article licensed under the terms of the Creative Commons Attribution Non-Commercial License (http://creativecommons.org/licenses/by-nc/3.0/) which permits unrestricted, non-commercial use, distribution and reproduction in any medium, provided the work is properly cited. 